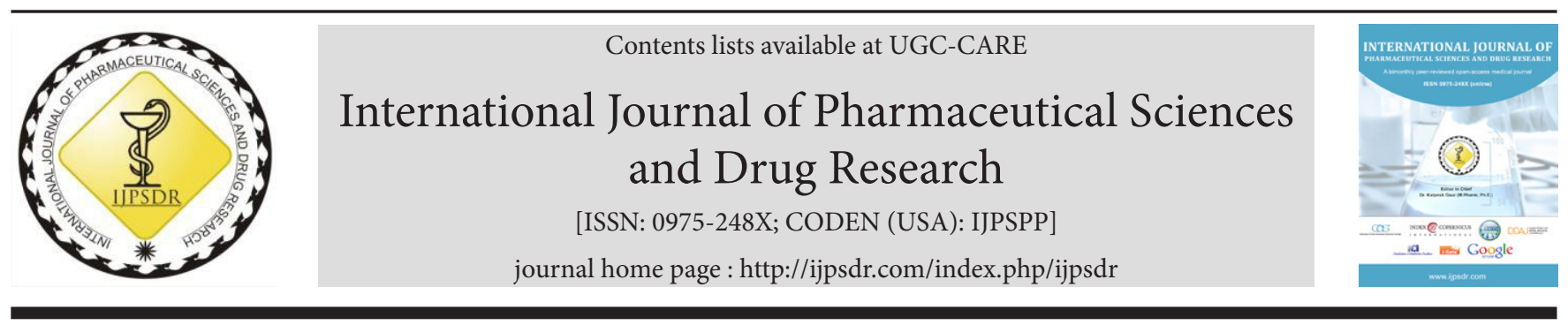

Research Article

\title{
Curcumin Reverses the Scopolomine-induced Cognitive Impairment by iNOS and Acetylcholinesterase Inhibition in Rodent Model of Schizophrenia
}

\author{
Henna Khan ${ }^{1 *}$, Amit Chaudhary ${ }^{2}$, Rashid Ali Khan ${ }^{3}$, Wazid Ali ${ }^{4}$ \\ ${ }^{1}$ School of Pharmacy, Monad University, N.H. 9, Delhi Hapur Road, Village \& Post Kastla, Kasmabad, P.O. Pilkhuwa-245304, Dist. Hapur, Uttar Pradesh, \\ India \\ ${ }^{2}$ School of Pharmacy, Abhilashi University, Chailchowk, Distt-Mandi-175028, Himachal Pradesh, India. \\ ${ }^{3}$ Department of Pharmaceutical Medicine, School of Pharmaceutical Education and Research, Jamia Hamdard, New Delhi-110062, India. \\ ${ }^{4}$ Department of Critical Care and Emergency Medicine, Sir Ganga Ram Hospital, New Delhi-110060, India.
}

\begin{tabular}{l} 
A R T I C L E I N F O \\
\hline Article history: \\
Received: 07 January, 2020 \\
Revised: 26 February, 2020 \\
Accepted: 04 March, 2020 \\
Published: 30 March, 2020 \\
Keywords: \\
Acetylcholinesterase, \\
Cognition, \\
Curcumin, \\
iNOS inhibition, \\
Schizophrenia. \\
D0I: \\
10.25004/IJPSDR.2020.120205
\end{tabular}

\section{INTRODUCTION}

Schizophrenia, a psychiatric disorder, typically emerges during a later stage of adolescence or early phase of adulthood. ${ }^{[1]}$ In Schizophrenia, cognitive impairment is a prominent feature characterized by dysfunction in learning, memory, verbal fluency, impairment in processing speed, and executive function. ${ }^{[2,3]}$ Additionally,

\begin{abstract}
A B S T R A C T
Schizophrenia is a severe neuro-developmental psychiatric disorder. Curcumin is a polyphenolic compound extracted from turmeric. It is known for its antioxidant, anti-inflammatory, neuroprotective, and precognitive properties. The purpose of the current study was to evaluate the role of curcumin in scopolamine-induced cognitive impairment in an animal model of schizophrenia. The elevated plus-maze test was utilised to study the curcumin effect on learning and memory. Curcumin (100 mg/kg, i.p.) was administered daily for 28 days in animals. Behavioral tests such as transfer latency (TL) and spontaneous alteration behavior was assessed after the last dose of curcumin on the 28th day, followed by biochemical estimations. The present study reported that curcumin showed an anti-amnesic effect in animal models of cognitive impairment of schizophrenia. Curcumin reduced the TL compared to a toxic control group (scopolamine per se) $(\mathrm{p}<0.001)$ in elevated plus-maze. In a spontaneous alteration behavior test, curcumin significantly increased percentage alteration and possible alteration as compared to the toxic control group ( $[p<0.001)$. A significant change in acetylcholinesterase activity, nitrate, and oxidative parameters was observed, thus, confirming its anti acetylcholinesterase, NOS (nitric oxide synthase) inhibition and antioxidant properties $(\mathrm{p}<0.05)$. The present study put forward the claim of curcumin as a new and safer therapeutic alternative for the treatment of cognitive impairment in Schizophrenia. The underlying mechanism of this potential effect may be related to anticholinesterase and nitric oxide synthase inhibition activity of curcumin. Further research is warranted for confirming the suggested pathways accountable for memory alleviating effects of curcumin in Schizophrenia.
\end{abstract}

\footnotetext{
*Corresponding Author: Mrs. Henna Khan

Address: School of Pharmacy, Monad University, Hapur-245101, Uttar Pradesh, India

Tel.: +91-9873716035

Email $\bowtie:$ hennakhan19@gmail.com

Relevant conflicts of interest/financial disclosures: The authors declare that the research was conducted in the absence of any commercial or financial relationships that could be construed as a potential conflict of interest.

Copyright (C) 2020 Henna Khan et al. This is an open access article distributed under the terms of the Creative Commons Attribution- NonCommercialShareAlike 4.0 International License which allows others to remix, tweak, and build upon the work non-commercially, as long as the author is credited and the new creations are licensed under the identical terms.
} 
Curcumin Reverses the Scopolomine-induced Cognitive Impairment by iNOS and Acetylcholinesterase Inhibition...

challenges with the newer atypical antipsychotics remain enormous. Many antipsychotics showed anticholinergic properties and failed to balance neurochemical alteration due to dopaminergic and cholinergic axis attributed to schizophrenia. ${ }^{[5]}$

Cognitive impairment is associated with cholinergic dysfunctions such as attention and memory deficit and executive dysfunction. ${ }^{[6]}$ Cholinergic hyperactivity is reported even in the prodromal phase of schizophrenia, which led to downgraded acetylcholine (ACh) levels that cause cognitive dysfunction as well as behavioral and psychological symptoms in schizophrenia. Degradation of acetylcholine leads to inflammation in central as well as peripheral nervous systems, which, in turn, increases central and peripheral AChE activity. ${ }^{[7]}$ Nitric oxide (NO) is intra and intercellular signaling molecule in the brain, which is responsible for the mechanisms of synaptic plasticity in the hippocampal synapses and is vital in cognition. ${ }^{[8]}$ The excess production in nitric oxide might be a contributing factor to the pathogenesis of schizophrenia. ${ }^{[9]}$

Curcumin, also known as turmeric (diferuloylmethane) [1,7-bis(4-hydroxy-3-methoxyphenyl)-1,6-heptadiene-3,5dione] is a natural polyphenolic compound from the powdered extract of a plant rhizome Curcuma longa (family Zingiberaceae). ${ }^{[10]}$ Curcumin is well acknowledged for antiseptic, anti-oxidant, and anti-inflammatory pharmacological properties. Curcumin is a potent antioxidant even when administered at a lower dose and acts by targeting various sources, causing oxidative stress. In addition, curcumin acts as a scavenger of free radicals, including superoxide, hydroxyl, and peroxyl radicals. ${ }^{[11]}$ Curcumin is also known for its role of inhibiting iNOS (an inducible form of NOS), which is a catalyst in NO production along with inhibiting NO-based free radicals like NO and peroxynitrite. ${ }^{[12,13]}$ Curcumin can be a potential agent for preventing and treating neurodegenerative disorders both NO and microglial cell-mediated ones. ${ }^{[14,15]}$ Additionally, it also exhibits anti-acetylcholinesterase activity. ${ }^{[16,17]}$

There are very few studies that report the effects of curcumin in treating psychiatric disorders except the ones which are confined to stress and depression. After critically reviewing properties of anti-inflammatory, antioxidant, iNOS inhibition, and anti acetylcholinesterase properties of curcumin, which hold promise in ameliorating cognitive impairment, our study evaluated curcumin's role in animal models of cognitive impairment for schizophrenia induced by scopolamine.

\section{MATERIALS AND METHODS}

\section{Animals}

Central animal house of Monad University provided required mice strain (swiss albino) with a weight of 25-35 mg then all animals were acclimatized in the environment of the University Animal House. The light-dark cycle of 12 hours was given with free access to food (pellet feed and water) to each animal for the entire duration of the study (28 days). A protocol of the current study was permitted by the Animal Ethics Committee, Monad University (Registration no. 1933/P0/Re/S/17CPCSEA), with project code no. ARFC/SOP/IAEC/15/18-19. All animals were taken care of in accordance with committee for the purpose of control and supervision of experiments on animals (CPCSEA) guidelines of the Department of Animal Welfare, India. Study animals were arranged in different groups. Every experimental group had six animals each.

\section{Drugs and Chemicals}

Test drug (curcumin) and drugs of toxic control (scopolamine) were purchased in pure form by Sigma Aldrich (USA). On the day of drug administration, peanut oil was used as a vehicle for curcumin to get desired concentration for study (100 mg/kg, p.o.). Other drugs to be used in the study were prepared in normal saline to get the required concentration. The analytical grade chemicals and reagents were used in the present study.

\section{METHODOLOGY}

In the present study, five groups with six animals in each group were formed. Groups were formed as peanut oiltreated mice in group I, normal control saline-treated mice in group II, scopolamine treated as toxic control in group III, curcumin per se treated mice in group IV, and co-administration of curcumin with scopolamine treated mice in group $\mathrm{V}$. The dose of curcumin was selected in accordance with preliminary experiments. Both curcumin (100 mg/kg) and scopolamine $(0.5 \mathrm{mg} / \mathrm{kg}$, p.o.) was given through intraperitoneal (i.p.) route. The treatment schedule of curcumin was daily for 28 days, while scopolamine was administered as a single dose on the last day of study ( $28^{\text {th }}$ day). All the behavioral experiments were executed on the last day of study, 1-hour after the last dose of study drug. After behavioral tests, animals were sacrificed as per the CPCSEA guidelines, followed by the removal of mice brains for biochemical examinations.

\section{Elevated Plus-maze Test}

This test is an effective and validated animal model to assess the drugs showing potential in learning and memory. The framework of model was made with acrylic resin, consisted of two closed arms in $5 \times 30 \times 15 \mathrm{~cm}$ dimensions and two open arms in $5 \times 30 \mathrm{~cm}$ dimensions facing each other. The entire main framework of the apparatus was elevated above the floor at height of $40 \mathrm{~cm}$. The closed arms were given black color while open arms and central platform were given white color and cellophane cover. In an elevated plus-maze test, an acquisition trial and retention trial was performed on day 1 and day 2, respectively, at the same time. In the acquisition trial, each experimental animal was kept gently at one end of open arms in a direction, which faces away 
from the central platform of a maze. Then, TL, which is time taken by each animal to enter any closed arms was noted. All mice were permitted to walk around every arm of plus-maze individually for 150 seconds. If the mice did not explore the closed arm within a time of 90 seconds in the acquisition trial, they were given physical motivation to do so on the back with a gentle push for an extra 60 seconds. In such a situation, only 90 seconds were recorded as TL. After 24 hours of acquisition trial, a retention trial was executed in a similar manner, and the same time on day 1 and TL was recorded again. In retention trial on day 2 , if the mice did not explore the any of the two closed arms in the time limit of 90 seconds, then the trial was terminated with a reading of 90 seconds as TL. ${ }^{[18]}$ The present study conducted these experiments between 11:00 am and 3:00 pm in a semi-sound proof room with dim lighting.

\section{Spontaneous Alternation Behavior}

Spontaneous alternation behavior method (SAB) was performed to assess the effect of study drug on shortterm memory in accordance with spatial orientation and perception in a plus-maze. ${ }^{[19]}$ Each mouse was placed individually in a plus-maze apparatus. The framework of maze was constructed with grey painted wood at $85 \mathrm{~cm}$ height and consisted of a central platform with dimensions of $25 \mathrm{~cm}$ diameter with four radiated and symmetrical arms of $55 \mathrm{~cm}$ long $\times 10 \mathrm{~cm}$ wide dimensions and walls of $12 \mathrm{~cm}$. Each experimental animal was kept gently at the central platform of the maze and then allowed to pass through the maze freely for a total of 12 mins. The total number of entries and its order were noted after the experiment for each animal. In SAB, the entry of mice into any of four different arms of a maze on an overlapping quintuple set of the sequence was defined as an alteration. A quintuple set was made up of five consecutive arm choices of mice within the total count of a set of arm selection. A quintuple with arm selection A, B, A, C, D was measured as an alternation of mice, while the set consisting $A, B, A, C$, $B$ was not considered as alternation of mice. Further, the total number of arm entries minus four were assumed as possible alternation sequence. In accordance with these assumptions, the percentage of alternation is equivalent to the ratio of actual alternation and possible alternation multiplied by a hundred.

\section{Biochemical Parameters}

\section{Estimation of Brain Acetylcholinesterase (AChE)}

Brains of mice were taken out by the decapitation method. The brain of each mouse was weighed and then kept at a temperature of $-70^{\circ} \mathrm{C}$. The present study assessed brain AChE activity in accordance with the method demonstrated by Ellman et al. 1961. ${ }^{[20]}$ Brain tissue with known weight was homogenized in sucrose solution $(0.32 \mathrm{M})$ to form a homogenate of $10 \%$. Further, this homogenate was then subjected to a series of centrifugation with different rpm and time but under a constant temperature of $4^{\circ} \mathrm{C}$. The first centrifugation was at $3000 \mathrm{rpm}$ for 15 minutes; then another centrifugation was carried out at 10,000 rpm for 10 minutes. After that, $1 \%$ of post mitochondrial supernatant was prepared by blending $1 \mathrm{~mL}$ of supernatant with $9 \mathrm{~m}$ : of sucrose solution. A mixture of $2.7 \mathrm{~mL}$ of phosphate buffer, $0.1 \mathrm{~mL}$ of DTNB, and $0.1 \mathrm{~mL}$ of PMS was used to form test samples. The reaction mixture was kept in a cuvette with caution and then carried out 5 minutes of pre-incubation. In the end, acetyl thiocholine iodide in a volume of $0.1 \mathrm{~mL}$ was included in the mixture to start the final reaction. Absorbance was recorded immediately at $412 \mathrm{~nm}$ for every 1-minute interval for 3 minutes. The present study assessed concentrations of protein utilizing the standard of purified bovine serum albumin in accordance with the method demonstrated by Lowry et al. 1951. [21]

\section{Nitric Oxide Synthase (NOS) Activity}

The present study incubated preserved whole brains in cell-culture media and assessed nitrate levels in accordance with the principles of Griess reagent reaction. Once the incubation period finished, $45 \mu \mathrm{L}$ of the Grace's Medium was transferred into the first set of centrifuge tubes subsequent to each group from the microtiter wells. NADPH and nitrate reductase were included to transform nitrates to nitrites. After that, gentle centrifugation at $8,175 \mathrm{x}$ g was carried out for two minutes. A $30 \mu \mathrm{L}$ of the supernatant was taken out from the centrifuge tubes of the first set into the corresponding tubes of the second set. At the end of the assay, griess reagent was mixed in a ratio of $1: 1$, followed by incubation of 5 to 10 minutes. Assay was performed with a microplate reader at $540 \mathrm{~nm}$ wavelength with a reference wavelength of $620 \mathrm{~nm} .^{[22,23] \text {. }}$

\section{Thiobarbituric Acid Reactive Substances (TBARS)}

Tissue homogenate (10\%) was prepared and suspension medium (1 $\mathrm{mL})$ was pipetted out from supernatants of the prepared tissue homogenate. Then centrifugation was carried out at a speed of 10,000 rpm. In the collected supernatant, $0.5 \mathrm{~mL}$ of $30 \%$ TCA was added. After that $0.5 \mathrm{~mL}$ of $0.8 \%$, TBA was also added. All the tubes were enclosed by aluminum foil and then put it gently in a trembling water bath for about 30 minutes at a temperature of $80^{\circ} \mathrm{C}$. Then tubes were removed from water bath followed by keeping in water (ice-cold) for about 10 minutes. After that, centrifugation was carried out again at a speed of 3,000 rpm for about 15 minutes. The supernatant was collected, and then its absorbance was recorded against a blank, which is consist of distilled water $(1.0 \mathrm{~mL}), \mathrm{TBA}(0.5 \mathrm{~mL})$, and TCA $(0.5 \mathrm{~mL})$, at a wavelength of $540 \mathrm{~nm}$ at room temperature. ${ }^{[24]}$

\section{Glutathione (GSH)}

The brain tissue of mice was homogenized in $0.02 \mathrm{M}$ of EDTA (6\%). Then we mixed $4 \mathrm{~mL}$ of distilled water in $5 \mathrm{~mL}$ of this homogenate followed by mixing $1 \mathrm{~mL}$ of $50 \%$ TCA. 
After that, all tubes were shaken to mix all constituents for at least 10-15 minutes. After this, all tubes were centrifuged at a speed of $300 \mathrm{rpm}$ for only 1-minute. Then, we mixed $2 \mathrm{~mL}$ of supernatant with $0.1 \mathrm{~mL}$ DTNB and $0.4 \mathrm{M}$ tris buffer ( $4 \mathrm{~mL}$ ) at $\mathrm{pH}$ 8.9. After that, absorbance was recorded immediately or within 5 minutes of the DTNB addition at a wavelength of $410 \mathrm{~nm}$ against a blank reagent without any homogenate. ${ }^{[25]}$

\section{Catalase}

A tissue homogenate (10\%) of the mice brain was prepared in $2 \mathrm{~mL}$ potassium phosphate buffer with $\mathrm{pH} 7.4$ followed by centrifugation of homogenate for 15 minutes at $3,000 \mathrm{rpm}$. The supernatant was collected, and catalase activity was measured in it. After that $2.95 \mathrm{~mL}$ of $\mathrm{H}_{2} \mathrm{O}_{2}$ (19 mM) was kept in a cuvette. Further, cytosolic supernatant $(0.05 \mathrm{ml})$ was added to the mixturekept in a cuvette, and then a change in absorbance noted at $240 \mathrm{~nm}$ for 3 minutes on 1-minute interval. ${ }^{[2]}$

\section{Statistical Analysis}

All data has been demonstrated as mean \pm SEM. We performed statistical analysis through Graph pad software. Analysis of variance (ANOVA) was utilized for evaluating the means of group then a test of Dunnett's multiple comparisons was utilized to assess the variation among groups. A p-value of $\leq 0.05$ was marked as statistically significant.

\section{RESULTS}

\section{Curcumin's Effect on Transfer Latency}

The present study assessed TL on days 1 and 2 after scopolamine administration $(0.5 \mathrm{mg} / \mathrm{kg}$, i.p.) and recorded a TL prolongation in comparison to control groups on both days. Further, it was reported that curcumin administration (100 mg/kg, i.p.) showed a reduction in TL on day 2 in comparison to TL recorded on day 1. Concurrent administration of curcumin and scopolamine also exhibited a significant reduction in transfer latency in comparison to scopolamine per se (toxic control) on both days 1 and $2(\mathrm{p}<0.001)$ (Table 1$)$.

\section{Effect of Curcumin on Spontaneous Alteration Behaviour}

It was reported that, scopolamine $(0.5 \mathrm{mg} / \mathrm{kg})$ reduced percentage and possible alteration significantly in comparison to control groups ( $\mathrm{p}<0.001)$. Curcumin per se group (100 mg/kg, i.p) administration showed an increase in percentage alteration but did not reach a significant level in comparison to control groups. Further, curcumin per se effect on possible alteration was also nonsignificant as compared to control groups, but concurrent administration of curcumin and scopolamine significantly increased percentage alteration and possible alteration in comparison to a group of toxic control $(\mathrm{p}<0.001)$ (Table 2$)$.

\section{Effect of Curcumin on Acetylcholinesterase Levels}

The present study reported that scopolamine per se $(0.5 \mathrm{mg} / \mathrm{kg})$ displayed an increase in AchE levels significantly when compared to control $(\mathrm{p}<0.05)$. Curcumin per se group (100 mg/kg, i.p) displayed a decrease in ACLE level when compared to control $(\mathrm{p}<0.05)$. Administering curcumin concurrently with scopolamine also displayed a decrease in level of AChE significantly when compared to toxic control, scopolamine ( $\mathrm{p}<0.05)$ (Fig. 1).

\section{Curcumin's Effect on Nitrite Levels}

The present study reported a decrease in nitrite levels significantly in the curcumin group in an elevated plusmaze model in comparison to the vehicle control $(\mathrm{p}<0.05)$. Further, concurrent curcumin administration $(100 \mathrm{mg} / \mathrm{kg})$

Table 1: Curcumin's effect on transfer latency

\begin{tabular}{lllll}
\hline & & $T L(\mathrm{sec})$ & Day 2 \\
\cline { 3 - 4 } Group no. $(\mathrm{n}=6)$ & Drugs & Dosage $(\mathrm{mg} / \mathrm{kg})$ & Day 1 & $10.21 \pm 0.35$ \\
I & Peanut oil & $1 \mathrm{~mL}$ & $24.01 \pm 2.72$ & $9.14 \pm 0.49$ \\
II & Saline & $1 \mathrm{~mL}$ & $22.32 \pm 1.66$ & $46.43 \pm 3.6^{* * *}, @ @ @$ \\
III & SCOP & 0.5 & $54.37 \pm 5.16^{* * *, @ @ @ ~}$ & $12.78 \pm 2.23$ \\
IV & Curcumin per se & 100 & $26.38 \pm 1.88$ & $31.76 \pm 4.45^{* * *}$,@@@,\#\#\# \\
V & Curcumin + SCOP & $100+0.5$ & $42.33 \pm 5.78^{* * *, @ @ @, \# \# \#}$ \\
\hline
\end{tabular}

SCOP: Scopolamine. Data were demonstrated as mean \pm SEM. Significance value: ${ }^{*} \mathrm{p}<0.05, * * * \mathrm{p}<0.001$ (vs. vehicle control, peanut oil). ${ }^{@}$ $\mathrm{p}<0.05,{ }^{@ @ @ ~} \mathrm{p}<0.001$ (vehicle control, saline). \# $\mathrm{p}<0.05$, \#\#\# p $<0.001$ (vs. toxic control, scopolamine)

Table 2: Curcumin's effect on spontaneous alteration behavior

\begin{tabular}{lllll}
\hline Group no. $(\mathrm{n}=6)$ & Drugs & Dosage $(\mathrm{mg} / \mathrm{kg})$ & \% Alteration & Possible alteration (sec) \\
\hline I & Peanut oil & $1 \mathrm{~mL}$ & $47.42 \pm 4.15$ & $29.13 \pm 2.5$ \\
II & Saline & $1 \mathrm{~mL}$ & $48.77 \pm 3.71$ & $30.56 \pm 2.2$ \\
III & SCOP & 0.5 & $27.37 \pm 1.79^{* * *}, @ @ @$ & $11.27 \pm 0.18^{* * *}, @ @ @$ \\
IV & Curcumin per se & 100 & $52.49 \pm 7.24$ & $24.43 \pm 2.2^{\prime}$ \\
V & Curcumin + SCOP & $100+0.5$ & $39.78 \pm 5.68^{* * *}, @ @ @, \# \# \#$ & $17.36 \pm 1.09^{* * *, @ @ @, \# \#}$ \\
\hline
\end{tabular}

SCOP: Scopolamine. Data was demonstrated as mean \pm SEM. Significance value: ${ }^{*} \mathrm{p}<0.05,{ }^{* * *} \mathrm{p}<0.001$ (vs. vehicle control, peanut oil).

${ }^{\circledR} \mathrm{p}<0.05$, ${ }^{@ @ ~} \mathrm{p}<0.001$ (vehicle control, saline). \# $\mathrm{p}<0.05, \# \# \mathrm{p}<0.01, \# \# \# \mathrm{p}<0.001$ (vs. toxic control, scopolamine) 


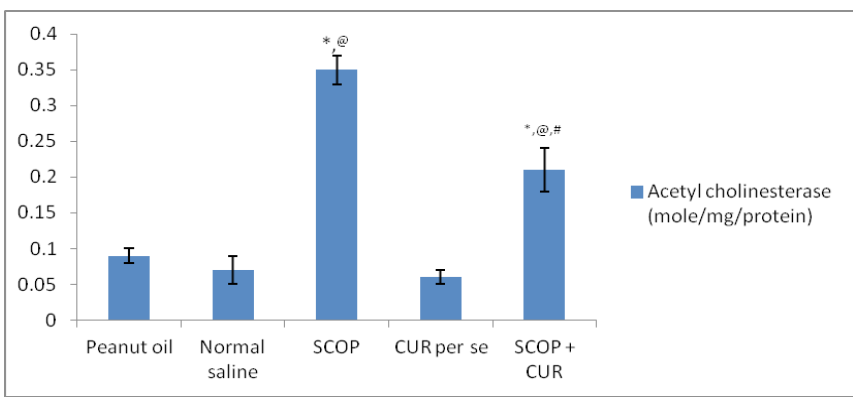

Fig. 1: Curcumin's effect on acetylcholinesterase activity CUR: Curcumin; SCOP: Scopolamine. Data were demonstrated as mean \pm SEM. Significance value: ${ }^{*} \mathrm{p}<0.05$ (vs. vehicle control, peanut oil). ${ }^{\circledR} \mathrm{p}<0.05$ (vehicle control, saline). \# $\mathrm{p}<0.05$ (vs. toxic control, scopolamine)

with toxic control scopolamine $(0.5 \mathrm{mg} / \mathrm{kg})$ attenuated the plasma nitrite levels significantly in comparison to toxic control ( $\mathrm{p}<0.001$ ) (Fig. 2).

\section{Curcumin's Effect on TBARS, GSH, and Catalase Levels}

The present study reported a significant reduction in TBARS level but an increase in GSH and catalase levels in the curcumin group $(100 \mathrm{mg} / \mathrm{kg})(\mathrm{p}<0.05)$. Scopolamine $(0.5 \mathrm{mg} / \mathrm{kg})$ with curcumin group also significantly reduced TBARS levels but increased GSH and catalase levels in comparison to toxic control ( $\mathrm{p}<0.05)$ (Fig. 3).

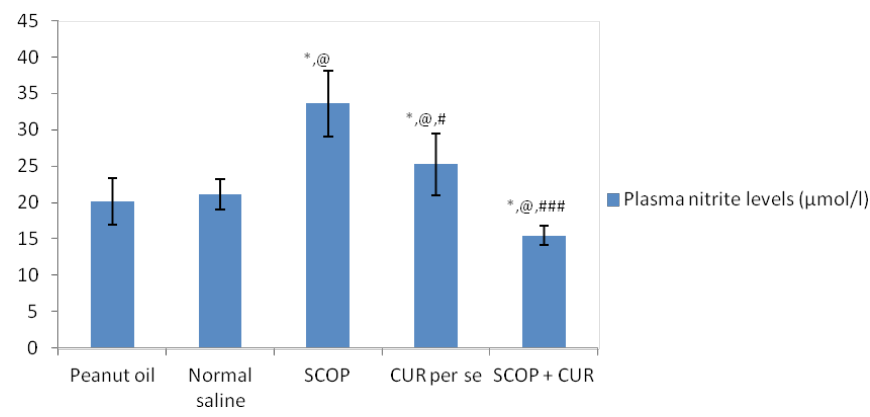

Fig. 2: Curcumin's effect on nitrite levels CUR: Curcumin; SCOP: Scopolamine. Data were demonstrated as mean \pm SEM. Significance value: ${ }^{*} \mathrm{p}<0.05$ (vs. vehicle control, peanut oil). ${ }^{@} \mathrm{p}<0.05$ (vehicle control, saline). \#p $<0.05$, $\# \# \#$ p $<0.001$ (vs. toxic control, scopolamine)

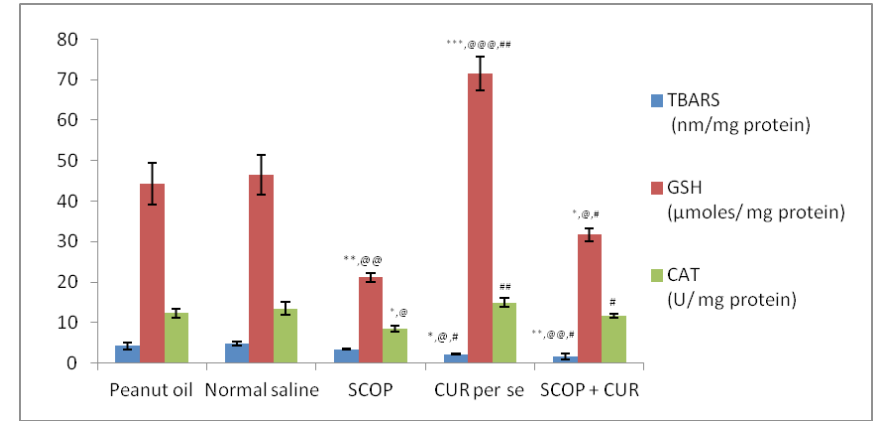

Fig. 3: Curcumin's effect on TBARS, GSH and CAT levels CUR: Curcumin; SCOP: Scopolamine. Data were demonstrated as mean \pm SEM. Significance value: ${ }^{*} \mathrm{p}<0.05,{ }^{* *} \mathrm{p}<0.01,{ }^{* * *} \mathrm{p}<0.001$ (vs. vehicle control, peanut oil). ${ }^{@} \mathrm{p}<0.05,{ }^{@} @ \mathrm{p}<0.01$, ${ }^{@ @ ~} \mathrm{p}<0.001$ (vehicle control, saline). \#p $<0.05, \# \# p<0.01$ (vs. toxic control, scopolamine)

\section{Discussion}

In this study, we evaluated the potential role of curcumin on cognitive impairment induced by scopolamine in an elevated plus-maze model and reported its anti-amnesic effect in schizophrenia.

Scopolamine is a muscarinic cholinergic antagonist that acts by blocking muscarinic receptors along with the impairment of long-term potentiation and the central cholinergic system. In animal models, scopolamine has been widely used for creating disruption in memory and learning. ${ }^{[27,28]}$

In the present study, scopolamine increased the TL compared to the group treated with vehicle in the elevated plus-maze test. Ameliorating effects of our test drug curcumin in learning and memory are implicated through its action of reducing the prolonged transfer latency induced by scopolamine in elevated plus-maze test. Our study reported that these behavioral results might be associated with a reduction in AChE activity due to curcumin in mice brain.

Our study also adopted SAB as one of the determinants of memory in line with a previous study. ${ }^{[19]}$ In this elevated plus maze test, animals treated with scopolamine demonstrated a reduction in percentage alteration as compared to animals treated with vehicle. Pre-treatment with curcumin displayed an increase in percentage alteration significantly when compared to the vehicle control group who were treated with peanut oil confirming curcumin's anti-amnesic effects.

A recent animal study also reported that curcumin prevented disruption of memory retrieval induced by scopolamine by restoring Akt and GSK dephosphorylation. ${ }^{[29]}$ The current study showed an association of anti-amnesic effect of curcumin with its AChE inhibitory activity in line with a previous animal study reporting latent inhibition induced by scopolamine prevented by an AChE inhibitor. $^{[30]}$

The potential of NO in learning and memory function is well known. Imbalance of NO in the brains may result in cognitive impairment. ${ }^{[31]}$ Also, in our present study, we planned to evaluate curcumin's role as an inhibitor of NO synthase in cognitive impairment in elevated plusmaze test induced by scopolamine. This study reported an ameliorative effect of curcumin in line with a previous study wherein another NOS inhibitor, and thymoquinone improved cognitive impairment. ${ }^{[32]}$

It was reported that L-NAME, a NOS inhibitor, antagonized MK-801, and ketamine-induced memory impairment. ${ }^{[33]}$ Another animal study discussed morphine-induced memory impairment and the facilitation of retrieval. It linked it with the release or decreased synthesis of NO, which can be neutralized by NO synthase substrate. ${ }^{[34]}$

As per a new dissertation, schizophrenic rats can regain normal functioning of brain if drugs that reduce the NO production in the brain are administered. ${ }^{[35]}$ 
In an earlier preclinical study, curcumin has displayed neuroprotective, antioxidant, anti-inflammatory, as well as procognitive properties. ${ }^{[36]}$ Amelioration of cognitive impairment by curcumin reported in the present study is consistent with the findings of previous preclinical studies. $^{[37-39]}$

Various clinical studies have reported ameliorative actions of curcumin on attention, memory, and cognitive decline in many diseases where cognitive impairment is the main feature.$^{[40-42]}$ Also, a recent systematic review has reported that curcumin improves serum brainderived neurotrophic factor (BDNF) in both males and females. $^{[43]}$

Till date, few clinical studies assessed the effectiveness of add-on curcumin treatment in schizophrenic patients. ${ }^{[4,45]}$ The results of our study are in-line with the findings of a recent clinical trial conducted to evaluate the effectiveness of curcumin in patients with schizophrenia as an add-on therapy. ${ }^{[46]}$ Therefore, further studies with varying doses of curcumin need to be conducted to evaluate its effect on the animal models of schizophrenia.

Findings of the present study put forward the claim that curcumin can be used for treating cognitive impairment in schizophrenic patients. Also, the current study suggests the importance of cholinergic dysfunctions and role of NO in the etiology of schizophrenia which might be accountable for anti-amnesic effects of curcumin.

\section{CONCLUSION}

Promising results from the present study suggested that curcumin may improve cognitive impairment. Curcumin can be a novel and safer therapeutic alternative for managing and treating schizophrenia. This may be related to an underlying mechanism of anticholinesterase and NO synthase inhibition activity of curcumin. Further studies are necessary for clarifying the suggested pathways accountable for memory retentive effects of curcumin in schizophrenia.

\section{ACKNOWLEDGMENT}

We express special thanks to the staff of the animal house of Monad University, Hapur, for providing all the support and cooperation.

\section{REFERENCES}

1. Liu C, Everall I, Pantelis C, Bousman C. Interrogating the evolutionary paradox of schizophrenia: A novel framework and evidence supporting recent negative selection of schizophrenia risk alleles. Frontiers in Genetics. 2019;10:389.

2. Freedman R. Schizophrenia. N Engl J Med 349:1738-1749. Gage FH, DunnettSB, Bjorklund A (1984). Spatial learning and motor deficits in aged rats. Neurobiol Aging. 2003;5:43-48.

3. Hill SK, Reilly JL, Keefe RS, Gold JM, Bishop JR, Gershon ES, et al. Neuropsychological impairments in schizophrenia and psychotic bipolar disorder: findings from the Bipolar-Schizophrenia Network on Intermediate Phenotypes (B-SNIP) study. Am J Psychiatry. 2013 Nov;170(11):1275-1284.
4. Eum S, Hill SK, Rubin LH, Carnahan RM, Reilly JL, Ivleva EI, Keedy SK, Tamminga CA, Pearlson GD, Clementz BA, Gershon ES, Keshavan MS, Keefe RSE, Sweeney JA, Bishop JR. Cognitive burden of anticholinergic medications in psychotic disorders. Schizophr Res. 2017 Dec;190:129-135.

5. Baitz HA, Thornton AE, Procyshyn RM, Smith GN, MacEwan GW, Kopala LC, Barr AM, Lang DJ, Honer WG. Antipsychotic medications: linking receptor antagonism to neuropsychological functioning in first episode psychosis. J Int Neuropsychol Soc. 2012;18:717-727.

6. Moghaddam B, Javitt D. From revolution to evolution: the glutamate hypothesis of schizophrenia and its implication for treatment. Neuropsychopharmacology. 2012 Jan 1;37(1):4-15.

7. Tani M, Akashi N, Hori K, Konishi K, Kitajima Y, Tomioka H, Inamoto A, Hirata A, Tomita A, Koganemaru T, Takahashi A, Hachisu M. Anticholinergic Activity and Schizophrenia. Neurodegener Dis. 2015;15(3):168-74.

8. Prast $\mathrm{H}$, Philippu A. Nitric oxide as modulator of neuronal function. Progr Neurobiol. 2001;64:51-68.

9. Bernstein $\mathrm{HG}$, Bogerts B, Keilhoff G. The many faces of nitric oxide in schizophrenia. A review. Schizophr Res. 2005;78:69-86.

10. Salvioli S, Sikora E, Cooper EL, Franceschi C. Curcumin in cell death processes: a challenge for CAM of age-related pathologies. EvidenceBased Complementary and Alternative Medicine. 2007;4(2):181-90.

11. Fujisawa S, Atsumi T, Ishihara M, Kadoma Y. Cytotoxicity, ROSgeneration activity and radical-scavenging activity of curcumin and related compounds. Anticancer research. 2004 Mar 1;24(2B): 563-570.

12. Rao MN. Nitric oxide scavenging by curcuminoids. Journal of pharmacy and pharmacology. 1997 Jan 1;49(1):105-107.

13. Butterfield DA, Castegna A, Pocernich CB, Drake J, Scapagnini G, Calabrese V. Nutritional approaches to combat oxidative stress in Alzheimer's disease. The Journal of nutritional biochemistry. 2002 Aug 31;13(8):444-461.

14. Jung KK, Lee HS, Cho JY, Shin WC, Rhee MH, Kim TG, Kang JH, Kim SH, Hong S, Kang SY. Inhibitory effect of curcumin on nitric oxide production from lipopolysaccharide-activated primary microglia. Life sciences. 2006 Oct 19;79(21):2022-2031.

15. Gilhotra N, Dhingra D. GABAergic and nitriergic modulation by curcumin for its antianxiety-like activity in mice. Brain research. 2010 Sep 17;1352:167-175.

16. Akinyemi AJ, Oboh G, Fadaka AO, Olatunji BP, Akomolafe S. Curcumin administration suppress acetylcholinesterase gene expression in cadmium treated rats. Neurotoxicology. 2017 Sep;62:75-79.

17. Abbasi MA, Ilyas M, Sonia A, Shahwar D, Raza MA, Khan KM, Ashraf M, Afzal I, Ambreen N. Curcumin and its derivatives: Moderate inhibitors of acetylcholinesterase, butyrylcholinesterase and trypsin. Scientia Iranica. 2012 Dec 1;19(6):1580-3.

18. Miyazaki S, Imaizumi M, Onodera K. Ameliorating effects of histidine on scopolamine-induced learning deficits using an elevated plusmaze test in mice. Life sciences. 1995 Mar 31;56(19):1563-70.

19. Ragozzino ME, Pal SN, Unick K, Stefani MR, Gold PE. Modulation of hippocampal acetylcholine release and spontaneous alternation scores by intrahippocampal glucose injections. Journal of neuroscience. 1998 Feb 15;18(4):1595-601.

20. Ellman GL, Courtney KD, Andres Jr V, Featherstone RM. A new and rapid colorimetric determination of acetylcholinesterase activity. Biochemical pharmacology. 1961 Jul 1;7(2):88-95.

21. Classics Lowry O, Rosebrough N, Farr A, Randall R. Protein measurement with the Folin phenol reagent. J biol Chem. 1951;193:265-275.

22. Tsikas D. Analysis of nitrite and nitrate in biological fluids by assays based on the Griess reaction: appraisal of the Griess reaction in the L-arginine/nitric oxide area of research. Journal of Chromatography B. 2007 May 15;851(1-2):51-70.

23. Hall CN, Attwell D. Assessing the physiological concentration and targets of nitric oxide in brain tissue. The Journal of physiology. 2008 Aug 1;586(15):3597-3615.

24. Ohkawa H, Ohishi N, Yagi K. Assay for lipid peroxides in animal tissues by thiobarbituric acid reaction. Analytical biochemistry. 1979 Jun 1;95(2):351-358. 


\section{Henna Khan et al.}

25. Ellman GL. Tissue sulfhydryl groups. Archives of biochemistry and biophysics. 1959 May 1;82(1):70-77.

26. Claiborne AL. Catalase activity. CRC handbook of methods for oxygen radical research. 1985;1:283-284.

27. Golechha M, Bhatia J, Arya DS. Studies on effects of Emblica officinalis (Amla) on oxidative stress and cholinergic function in scopolamineinduced amnesia in mice. J Environ Biol 2012;33:95-100.

28. Alikatte KL, Akondi BR, Yerragunta VG, Veerareddy PR, Palle S. Antiamnesic activity of Syzygium cumini against scopolamine induced spatial memory impairments in rats. Brain Dev. 2012; 34:844-851.

29. SoukhakLari R, Moezi L, Pirsalami F, Ashjazadeh N, Moosavi M. Curcumin ameliorates scopolamine-induced mice memory retrieval deficit and restores hippocampal p-Akt and p-GSK-3 $\beta$. European journal of pharmacology. 2018 Dec 15;841:28-32.

30. Barak S, Weiner I. Scopolamine induces disruption of latent inhibition which is prevented by antipsychotic drugs and an acetylcholinesterase inhibitor. Neuropsychopharmacology. 2007 May;32(5):989-99.

31. Paul V, Ekambaram P. Involvement of nitric oxide in learning \& memory processes. Indian J Med Res. 2011 May;133:471-8.

32. Khan RA, Najmi AK, Khuroo AH, Goswami D, Akhtar M. Ameliorating effects of thy moquinone in rodent models of schizophrenia. African Journal of Pharmacy and Pharmacology. 2014 Apr 22;8(15): 413-421.

33. Boultadakis A, Pitsikas N. Effects of the nitric oxide synthase inhibitor L-NAME on recognition and spatial memory deficits produced by different NMDA receptor antagonists in the rat. Neuropsychopharmacology. 2010 Nov;35(12):2357.

34. Rezayof A, Amini R, Rassouli Y, Zarrindast MR (2006). Influence of nitric oxide on morphine-induced amnesia and interactions with dopaminergic receptor agents. Physiol. Behav. 88(1-2):124-131.

35. Göteborg University. "New Discoveries About Nitric Oxide Can Provide Drugs For Schizophrenia." ScienceDaily. ScienceDaily, 23 November 2007. Available From: www.sciencedaily.com/ releases/2007/11/071121213845.htm

36. Dong S, Zeng Q, Mitchell ES, Xiu J, Duan Y, Li C, Tiwari JK, Hu Y, Cao $\mathrm{X}$, Zhao Z. Curcumin enhances neurogenesis and cognition in aged rats: implications for transcriptional interactions related to growth and synaptic plasticity. PLoS One. 2012;7(2):e31211.
37. Chimakurthy J,Talasila M.Effects of curcumin on pentylenetetrazoleinduced anxiety-like behaviors and associated changes in cognition and monoamine levels. Psychology \& Neuroscience. 2010 Jul;3(2):239.

38. Rajasekar N, Dwivedi S, Tota SK, Kamat PK, Hanif K, Nath C, Shukla R. Neuroprotective effect of curcumin on okadaic acid induced memory impairment in mice. Eur J Pharmacol. 2013 Sep 5; 715(1-3):381-394.

39. Tiwari V, Chopra K. Attenuation of oxidative stress, neuroinflammation, and apoptosis by curcumin prevents cognitive deficits in rats postnatally exposed to ethanol. Psychopharmacology (Berl). 2012 Dec;224(4):519-535.

40. Fanaei H, Khayat S, Kasaeian A, Javadimehr M. Effect of curcumin on serum brain-derived neurotrophic factor levels in women with premenstrual syndrome: A randomized, double-blind, placebocontrolled trial. Neuropeptides. 2016 Apr 1;56:25-31.

41. Rainey-Smith SR, Brown BM, Sohrabi HR, et al. Curcumin and cognition: a randomised, placebo-controlled, double-blind study of community-dwelling older adults. Br J Nutr. 2016;115:21062113.

42. Cox KH, Pipingas A, Scholey AB. Investigation of the effects of solid lipid curcumin on cognition and mood in a healthy older population. J Psychopharmacol. 2015;29: 642-651.

43. Sarraf P, Parohan M, Javanbakht MH, Ranji-Burachaloo S, Djalali M. Short-term curcumin supplementation enhances serum brainderived neurotrophic factor in adult men and women: A systematic review and dose-response meta-analysis of randomized controlled trials. Nutrition Research. 2019 May 9.

44. Kucukgoncu S, Guloksuz S, Tek C. Effects of Curcumin on Cognitive Functioning and Inflammatory State in Schizophrenia: A Double-Blind, Placebo-Controlled Pilot Trial. Journal of clinical psychopharmacology. 2019 Mar 1;39(2):182-184.

45. Wynn JK, Green MF, Hellemann G, et al. The effects of curcumin on brain-derived neurotrophic factor and cognition in schizophrenia: a randomized controlled study. Schizophr Res. 2017;195:572-573.

46. Woodbury-FarinaM, Cernovsky Z, Chiu S, et al. Proof of concept of randomized controlled study of Curcumin C-3 Complex as adjunct treatment in schizophrenia: effects on negative and depressive symptoms. Ontario, Canada: Presented at Natural Bioactives Conference. 2012 July 9-12.

HOW TO CITE THIS ARTICLE: Khan H, Chaudhary A, Khan RA, Ali W. Curcumin reverses the scopolomine-induced cognitive impairment by inos and acetylcholinesterase inhibition in rodent model of schizophrenia. Int. J. Pharm. Sci. Drug Res. 2020; 12(2):122-128. DOI: 10.25004/IJPSDR.2020.120205 